Research paper

\title{
Brazilian propolis promotes immunomodulation on human cells from American Tegumentar Leishmaniasis patients and healthy donors infected with $L$. braziliensis
}

\author{
Ana Paula Fortes dos Santos Thomazelli ${ }^{\mathrm{a}, 1}$, Fernanda Tomiotto-Pellissier ${ }^{\mathrm{a}, *, 1}$, Suelen Santos da Silva ${ }^{\mathrm{a}, 1}$, \\ Carolina Panis ${ }^{\mathrm{b}}$, Tatiane Marcusso Orsini ${ }^{\text {a }}$, Allan Henrique Depieri Cataneo ${ }^{\text {a }}$, Milena Menegazzo Miranda- \\ Sapla ${ }^{a}$, Luiz Antonio Custódio ${ }^{c}$, Vera Lúcia Hideko Tatakihara ${ }^{c}$, Juliano Bordignon ${ }^{\mathrm{d}}$, Guilherme Ferreira \\ Silveira $^{\mathrm{d}}$, José Maurício Sforcin ${ }^{\mathrm{e}}$, Wander Rogério Pavanelli ${ }^{\mathrm{a}}$, Ivete Conchon-Costa ${ }^{\mathrm{a}}$ \\ ${ }^{a}$ Departamento de Ciências Patológicas, Centro de Ciências Biológicas, Universidade Estadual de Londrina, 86057-970 Londrina, Paraná, Brazil \\ ${ }^{\mathrm{b}}$ Laboratório de Mediadores Inflamatórios, Universidade do Oeste do Paraná, UNIOESTE, 85605-010 Francisco Beltrão, Paraná, Brazil \\ c Ambulatório de Especialidades do Hospital Universitário de Londrina, 86057-970 Londrina, Paraná, Brazil \\ ${ }^{\mathrm{d}}$ Laboratório de Virologia Molecular, Instituto Carlos Chagas/Fundação Oswaldo Cruz, 81350-010 Curitiba, Paraná, Brazil \\ ${ }^{\mathrm{e}}$ Departamento de Microbiologia e Imunologia, Instituto de Biociência, Universidade Estadual Paulista, UNESP, 18618-970 Botucatu, São Paulo, Brazil
}

\section{A R T I C L E I N F O}

\section{Article history:}

Received 7 May 2016

Revised 20 September 2016

Accepted 28 September 2016

Available online 29 September 2016

\section{Keywords:}

Th17

IL-4

IL-6

IL-10

Human PBMC

In vitro

\begin{abstract}
A B S T R A C T
American Tegumentar Leishmaniasis (ATL) is an infectious disease caused by Leishmania parasites with ineffective treatment. The properties of propolis have been studied in different experimental studies, however, few works have investigated the effects of propolis on human-derived peripheral blood mononuclear cells (PBMC) in leishmaniasis models. Thus, we investigate the immunomodulatory effects of propolis treatment on PBMC from ATL patients and on PBMC from healthy donors infected with Leishmania braziliensis. Our data demonstrate that propolis pretreatment shows immunomodulatory effects on both healthy donors and ATL patients adherent cells, increasing IL-4 and IL-17 and decreasing IL-10, in either the presence or absence of the L. braziliensis infection, demonstrating that propolis contributes with the decrease of the inflammation and could also contribute with parasite control.
\end{abstract}

(c) 2016 Elsevier Inc. All rights reserved.

\section{Introduction}

American Tegumentar Leishmaniasis (ATL) is an infectious disease caused by parasites of the genus Leishmania, spread by sand fly vectors [1]. This disease can result in a spectrum of clinical manifestations ranging from ulcerative lesions in the skin, mucosal or as no ulcerated nodules [2]. The immune response from the host and the parasite species are the main responsible factors to determine the clinical disease [2].

This parasitic disease is a serious public health problem due to the worldwide distribution in temperate, tropical and subtropical regions. Additionally, the available drugs for treatment are ineffective, its uses are restricted and they possesses high side effects, contributing to the spread of the infection $[3,4]$.

\footnotetext{
* Corresponding author.

E-mail address: fernandatomiotto@gmail.com (F. Tomiotto-Pellissier).

1 Authors with equal contribution.
}

Several studies have demonstrated the importance of a host parasite interaction on leishmaniasis pathogenesis [5,6]. Furthermore, experimental models have shown that the outcome of Leishmania infection is dependent on the activation of $\mathrm{CD}^{+} \mathrm{T}$ cell subsets $[7,8]$.

Studies of $L$. major infection in susceptible and resistant mice has demonstrated that protective immune responses against Leishmania are linked to development of a Th1 response and IFN $\gamma$ production. IFN $\gamma$ trigger macrophage activation leading to upregulation of inducible nitric oxide synthase (iNOS) and nitric oxide (NO) synthesis, promoting the elimination of intracellular parasites and control of disease. On the other hand, the disease progression has been associated with a development of Th2 responses and IL-4 production [5,8].

Besides Th1/Th2 profile, in recent years, Th17 response has been shown in infections caused by Leishmania spp. [9-11]. Th17 cells have proinflammatory properties and secrete primarily IL17. The role of IL-17 during Leishmania infection remains controversial and poorly defined. In a model of cutaneous leishmaniasis 
caused by Leishmania major, IL-17 production is associated with disease progression [12]; however, in human L. braziliensis infections, the opposite holds true [10]. Moreover, higher level of IL17 was found in the serum of asymptomatic individuals than in serum of $L$. donovani symptomatic patients [9].

Considering the characteristics of this disease and in the search of new drugs, propolis is a candidate because of its several biological properties described already (reviewed in [13]) highlighting its anti-inflammatory [14-16], immunomodulatory [17-19], wound healing and antileishmanial effect [20-25].

The major propolis components of our sample are phenolic compounds (flavonoids, aromatic acids and benzopyranes), diand triterpenes and essential oils [18]. In the experimental leishmaniasis, propolis was able to kill promastigote and amastigote forms of several Leishmania species [20,22-27]. Besides that, propolis components, such as prenylated compounds and benzophenones [22] have already been associated with the inhibition of amastigote proliferation by macrophage activation, or by direct effect on promastigote forms (caffeic acid, p-coumaric acid, aromadendrine-4'-methyl ether, 3-prenyl-p-coumaric and 3,5diprenyl-p-coumaric) [24].

Some works have reported that the propolis or some of its constituents suppresses inflammatory processes on human PBMC [2830]. However, there are few studies focusing on the action of propolis on human PBMC in experimental leishmaniasis [31].

Therefore, the aim of this study was to evaluate the immunomodulatory effect of propolis and $L$. braziliensis on adherent cells from ATL patients and healthy donors.

\section{Material and methods}

\subsection{Subjects}

This study included patients with ATL $(n=14)$, diagnosed by indirect immunofluorescence assay from serum, biopsies and clinical parameters, and patients with negative serology for HIV, HBV and HCV at Clinical Hospital of Universidade Estadual de Londrina, Paraná-PR, Brazil. Healthy donors $(n=9)$ were selected according to similar demographic characteristics and from the same geographic area. Parameters such as age and gender were controlled. All control individuals did not present either clinical symptoms or laboratory parameters of inflammation and negative to the leishmania skin test or other autoimmune diseases.

The peripheral blood of the ATL patients and healthy donors was collected only once, before the beginning of the standard treatment, therefore all assays were conducted only once per donor in triplicate.

All donors and researchers signed a consent term for blood collection. This study was approved by the Human Ethics Committee of the Universidade Estadual de Londrina and followed all institutional guidelines (257/08 - May 22, 2009).

\subsection{Hydroalcoholic extract of Brazilian propolis}

The propolis sample was collected in the Beekeeping Section of Lageado Farm, Universidade Estadual Paulista (UNESP), Campus of Botucatu, SP, from colonies of Apis mellifera L. bees. The extraction method as well as the chemical composition of this sample had been documented in previous studies in which chemical analysis showed that major constituents of this sample are phenolic compounds, such as flavonoids, aromatic acids and benzopyrans, as well as di and tri terpenes and essential oils [14]. The final concentration of ethanol solvent in the experiments did not exceed $0.1 \%$.

\subsection{Leishmania braziliensis promastigotes}

Leishmania (Viannia) braziliensis in promastigote forms (MHOM/ BR/1987/M11272) were maintained in culture medium 199 (GIBCO Invitrogen ${ }^{\circledR}$, Grand Island, USA), and supplemented with $10 \%$ fetal bovine serum (GIBCO Invitrogen ${ }^{\circledR}$, Grand Island, USA), $10 \mathrm{mM}$ of HEPES biological buffer (AMRESCO ${ }^{\circledR}$, Solon, USA), $1 \%$ human urine, $1 \%$ L-glutamine $\left(\right.$ Synth $^{\circledR}$, Diadema, Brazil), penicillin and streptomycin $\left(10 \mathrm{U} / \mathrm{mL}-10 \mu \mathrm{g} / \mathrm{mL}\right.$, GIBCO Invitrogen ${ }^{\circledR}$, Grand Island, USA), and $10 \%$ sodium bicarbonate $\left(\right.$ Synth $^{\circledR}$, Diadema, Brazil). The cell cultures were grown on a BOD type incubator at $24 \pm 25^{\circ} \mathrm{C}$ in $25 \mathrm{~cm}^{2}$ culture flask. In all experiments, there were used live promastigote forms in the stationary growth phase (5day culture)

\subsection{Human adherent cells culture and treatments}

PBMC enriched monocytes obtained from the heparinized blood of ATL patients and healthy control subjects were separated on Ficoll-Hypaque (Sigma ${ }^{\circledR}$ ) and maintained in RPMI 1640 medium supplemented with $10 \%$ fetal bovine serum (FBS), glutamine $(0,1 \%$, Invitrogen-Life Technologies) and penicillin-streptomycin $\left(10 \mathrm{U} / \mathrm{mL}-10 \mu \mathrm{g} / \mathrm{mL}\right.$, GIBCO Invitrogen ${ }^{\circledR}$, Grand Island, USA). Adherent cells $\left(5 \times 10^{5}\right.$ cells/well) were incubated in 24 well plates in the absence or presence of propolis at 5 and $25 \mu \mathrm{g} / \mathrm{mL}$ for $24 \mathrm{~h}$ at $37^{\circ} \mathrm{C}$ and $5 \% \mathrm{CO}_{2}$. When indicated, after propolis treatment, adherent cells were challenged with viable promastigote forms of Leishmania braziliensis $(5: 1)$ for $2 \mathrm{~h}$ and the supernatants were collected, centrifuged to remove debris and kept at $-76{ }^{\circ} \mathrm{C}$ until further analysis.

\subsection{Cytokine determination}

The Cytometric Bead Array Assay (CBA, BD Biosciences ${ }^{\circledR}$ ) was used to measure the levels of IL-2, IL-4, IL-6, IL-10, TNF- $\alpha$, IFN- $\gamma$ and IL-17 in serum or supernatants from adherent cells (patients and healthy controls) following the manufacturer's instructions.

\subsection{Determination of nitric oxide levels}

NO level was estimated as previously described [32], as total nitrite content in serum or supernatants of both ATL patients and healthy donors. In summary, both the treated and nontreated samples were deproteinized by adding $\mathrm{ZnSO}_{4}(50 \mu \mathrm{L}, 75 \mathrm{mM})$ and $\mathrm{NaOH}(70 \mu \mathrm{L}, 55 \mathrm{mM})$. The mixture was centrifuged $(10.000 \mathrm{rpm}$, $5 \mathrm{~min}$ ). The supernatant was recovered and diluted in glycine buffer solution ( $45 \mathrm{~g} / \mathrm{L} \mathrm{pH} 9.7)$. It was added cadmium granules previously activated with $\mathrm{CuSO}_{4}(5 \mathrm{mM})$ solution and left for $10 \mathrm{~min}$ at room temperature. After incubation, $50 \mu \mathrm{L}$ of the supernatant aliquots were transferred to 96-well microplates and the same volume of Griess reagent was added. Calibration curve was prepared by dilution of $\mathrm{NaNO}_{2}$ and the absorbances were measured at $550 \mathrm{~nm}$ in a microplate reader.

\subsection{Statistical analysis}

All experiments were conducted in triplicate. Statistical analysis was performed using the software GraphPad Prism 5.0 (Graph Pad, USA). Results were expressed as arithmetic means and standard errors of the means. Differences among the groups were assessed by Student's $t$-test or by One-way analysis of variance (ANOVA) followed by Tukey's post hoc test. All data were checked using the Grubbs test (GraphPad Quickcalcs) to eliminate significant outliers $(\mathrm{p}<0.05)$. A $\mathrm{p}<0.05$ was considered statistically significant. 


\section{Results}

\subsection{Clinicopathological data of patients}

Of the 14 patients available with ATL, 12 were women with age ranging between 33 to 71 years, with anti-Leishmania serology titles ranging from 1:40 to 1:320. The biopsies identified the presence of Leishmania parasites (15\%) and inflammatory infiltrates (30\%). In addition, clinical observations showed that $30 \%$ of patients were diagnosed with the ulcerous form of the disease, while $70 \%$ presented mixed forms (ulcer, crusting or scarring lesions). Furthermore, $40 \%$ of patients exhibited lesions in the lower limbs (Table 1).

\subsection{NO profile of serum from healthy donors and ATL patients}

Serum from both ATL patients and healthy donors was used to assess NO levels. Our results showed that NO production in ATL patients was 50\% lower than the results from healthy donors (Fig. 1).

\subsection{Effect of propolis extract on NO profile of adherent cells from healthy donors and ATL patients}

The NO levels in supernatant of adherent cells culture from ATL patients was reduced in comparison to healthy donors. When the adherent cells culture from healthy donors was treated with propolis $5 \mu \mathrm{g} / \mathrm{mL}$, the NO level reduced. In cells derived from ATL patients, the treatment with propolis ( 5 and $25 \mu \mathrm{g} / \mathrm{mL}$ ) was not able to restore NO levels (Fig. 2).

\subsection{Cytokine profile on adherent cells from healthy donors and ATL patients treated with Brazilian propolis}

When analyzed the role of propolis in immunomodulation of adherent cells from ATL patients and healthy donors, initially we observed that there was no difference in the IL- 4 levels in adherent cells from healthy donors and ATL patients, however the IL-10 concentration increased in cells from patients (Fig. 3). When examined the immunomodulatory role of propolis on adherent cells from donors (healthy and ATL patients), we found that only the concentration of $25 \mu \mathrm{g} / \mathrm{mL}$ was able to increase the IL-4 levels when compared with their respective controls and the group treated with $5 \mu \mathrm{g} / \mathrm{mL}$ (Fig. 3A). Regarding the IL-10 cytokine, we found that the treatment with $10 \mu \mathrm{g} / \mathrm{mL}$ maintained the high levels of this cytokine as the infected control, however the concentration of $25 \mu \mathrm{g} / \mathrm{mL}$ of propolis was able to reduce the concentration of IL10 in adherent cells from ATL patients to similar levels found in healthy donors (Fig. 3B).

The in vitro treatment of adherent cells from healthy donors and ATL patients with propolis was not able to affect the levels of IL-2, TNF- $\alpha$, IFN- $\gamma$ and IL-17. IL-6 level was not altered in the ATL treated group (Supplementary figure).

\subsection{Cytokine profile on adherent cells from healthy donors treated with Brazilian propolis and infected with L. braziliensis}

On the other hand, when cells from healthy donors were infected with Leishmania braziliensis, we observed that the pretreatment with propolis was able to increase IL- 6 cytokine levels $(5 \mu \mathrm{g} / \mathrm{mL}$ ) (Fig. $4 \mathrm{~A}$ ) and IL-17 (5 and $25 \mu \mathrm{g} / \mathrm{mL}$ ) (Fig. $4 \mathrm{C}$ ), but reduced the levels of IL-10 when compared to the infected control (Fig. 4B).
Table 1

Clinicopathological data of ATL patients. Patients diagnosed with American Tegumentar Leishmaniasis (by indirect immunofluorescence assay, biopsies and clinical parameters) from Clinical Hospital of the State University of Londrina, Brazil.

\begin{tabular}{ll}
\hline Parameter & Data \\
\hline Total number of patients & 14 \\
Female gender & $85 \%$ \\
Male gender & $15 \%$ \\
Mean age in years & $51(33-71)$ \\
$\quad$ (range) & $15 \%$ with the parasite identified in the biopsy 30\% \\
Histopathological & inflammatory infiltrate presence \\
$\quad$ findings & $1: 124$ \\
Mean titer of serology & for Leishmaniasis \\
Type of lesions & $30 \%$ ulcerous, 70\% ulcer, crusting or scarring \\
Site of infection & $40 \%$ lower limbs, 60\% face and neck \\
\hline
\end{tabular}

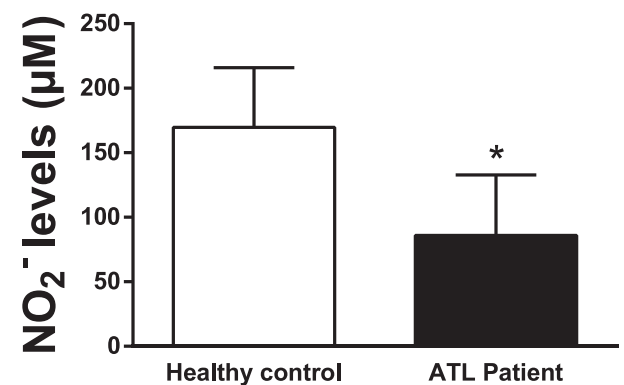

Fig. 1. Profile of NO from serum of healthy donors and ATL patients. The NO levels were evaluated in the serum of healthy donors $(n=9)$ and ATL patients $(n=14)$ by Cadmium-copper-Griess reaction. Results represent the mean \pm SEM of experiments performed in triplicate. "Significantly different from untreated healthy donors control (Student's $t$-test, $\mathrm{p}<0.05$ ).

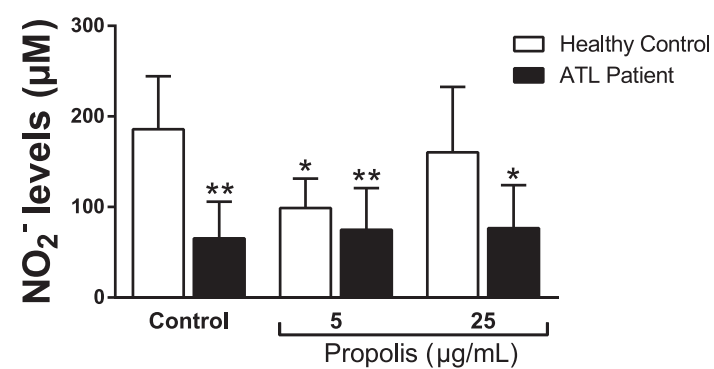

Fig. 2. NO profile of adherent cells from healthy donors and ATL patients treated with Brazilian propolis. The NO levels were evaluated in adherent cells from healthy donors $(n=9)$ and ATL patients $(n=14)$ with or without treatment with propolis 5 and $25 \mu \mathrm{g} / \mathrm{mL}$ for $24 \mathrm{~h}$, by Cadmium-copper-Griess reaction. One-way ANOVA followed by Tukey test. Results represent the mean \pm SEM of experiments performed in triplicate. Significantly different from untreated healthy donors control $\left({ }^{*} \mathrm{p}<0.05,{ }^{* *} \mathrm{p}<0.01\right)$.

\section{Discussion}

Leishmania is a parasite able to down regulate the production of several inflammatory mediators including nitric oxide (NO). In fact, several studies have shown that this adjustment can occur either by suppressing iNOS via glycocalyx components, or by consuming the precursor of NO (L-arginine) in its own metabolism, directly influencing the levels of this molecule, resulting in permanent of this pathogen in the host [33,34].

According to the literature, patients with ATL exhibit reduced levels of this mediator when compared to healthy donors. Consistent with the results found in the serum, we also observed reduced levels of NO in supernatant of adherent cells from ATL patients. 
A

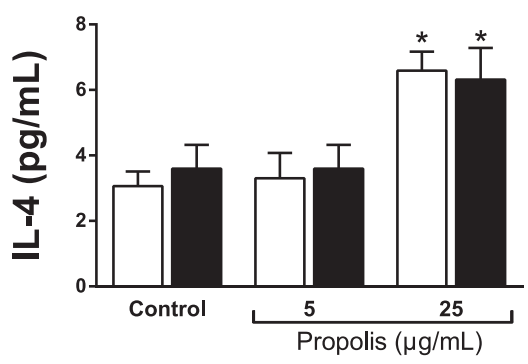

B

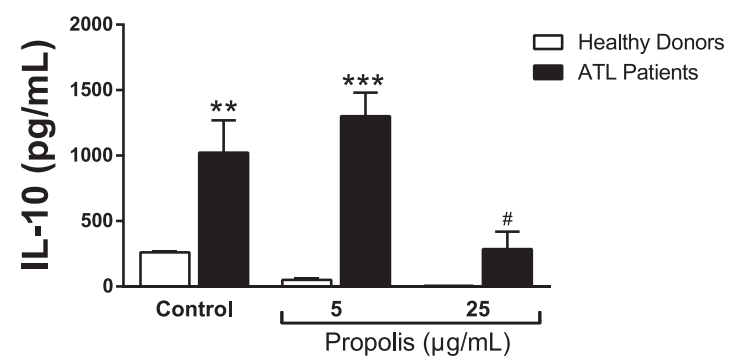

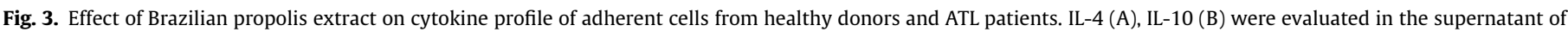

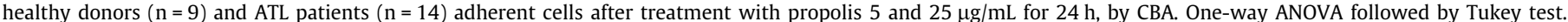

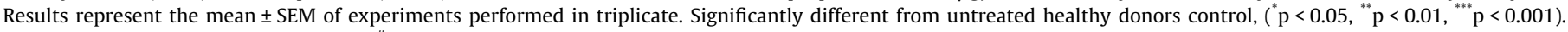
Significantly different from ATL control $\left({ }^{\#} \mathrm{p}<0.001\right)$.
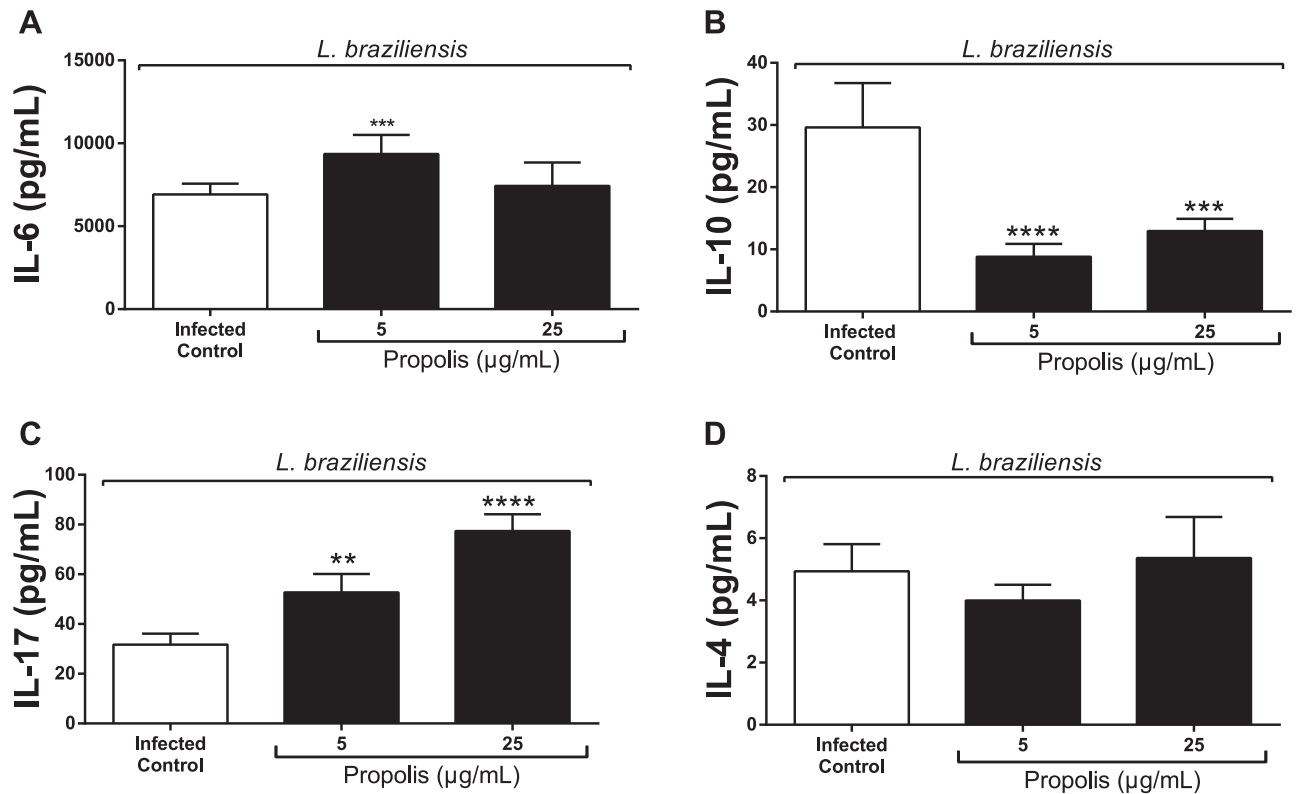

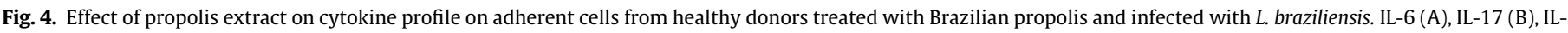

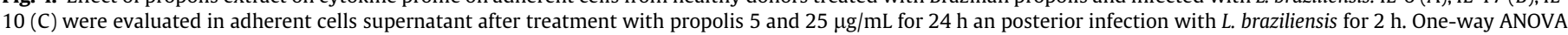

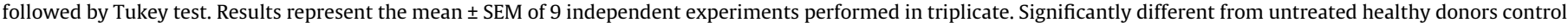
$\left({ }^{* *} \mathrm{p}<0.01,{ }^{* * *} \mathrm{p}<0.001,{ }^{* * * *} \mathrm{p}<0.0001\right)$.

Although NO is considered the most relevant microbicidal molecule, once the disease is installed, the presence of this molecule associated with intense activation of many other defense mechanisms, result in a strong inflammatory response, increasing tissue damage and exacerbation of the injury $[35,36]$.

As stated by [37], the development or discovery of drugs that can act on the pathogen's metabolism and also have an effect on the immune component should be subject of several studies.

It is known that propolis has been widely used in folk medicine, showing promising results in several disease models [17-19] and has a great potential to display a protective immune response against leishmaniasis $[20,21,38]$. We decided to evaluate its activity in adherent cells from healthy donors and ATL patients, and found that the treatment was not able to restore the levels of NO in the ATL group.

These results are explained by the fact that propolis by itself produces an anti-inflammatory effect through the inhibition of NO production [17,39], as we previously demonstrated.

Although propolis act in inhibiting the synthesis of NO, an important molecule for microbicidal host, it presents direct leish- manicidal $[20,38]$ and immunomodulatory effect on experimental Leishmania-infection model [20,21,38].

When evaluating the immunomodulatory activity of propolis on adherent cells, we found that IL-4 levels increased significantly $(25 \mu \mathrm{g} / \mathrm{mL})$, whereas the IL-10 production reduced $(25 \mu \mathrm{g} / \mathrm{mL})$. Subsequently, we verified whether the immunomodulation induced by propolis remains in adherent cells after infection with L. braziliensis. In cells treated with propolis, the infection was not able to reduce IL-17 levels ( 5 and $25 \mu \mathrm{g} / \mathrm{mL}$ ) and IL-6 $(5 \mu \mathrm{g} / \mathrm{mL}$ ), while treatment with propolis maintained IL-10 levels reduced even after infection ( 5 and $25 \mu \mathrm{g} / \mathrm{mL}$ ).

Although IL-4 is responsible for parasite resistance inside the infected cells [40] this is an important cytokine in the control of exacerbated inflammation, which occurs in ATL patients lesions [41]. Yao (2005) [42] demonstrated that the presence of IL-4 is responsible for inhibiting IL-10 production, a cytokine which is directly related to the progression of the leishmaniasis [43-45]. It is also known that combination of both cytokines are able to act in controlling inflammation (IL-10) and promotes fibrosis progression (IL-4), by stimulating the synthesis of types I and III collagen [46-49]. 
IL-6 is a pleiotropic cytokine with several functions in the immune response, including regulating Th17 response [50]. Th17 cells are responsible for synthesising various cytokines, including IL-17. Although it has been demonstrated that this cytokine could induce tissue damage and progression of the injury [51,52], it may also be important in the protection and clearance of the parasite $[10,11,53]$. Our results corroborate with Born's et al. study, which demonstrated that the IL-17 protects against Leishmania infection and is associated with downregulation of regulatory $T$ cells and IL-10 production, benefitting the Th1 response and improving the leishmanicidal activity of macrophages.

\section{Conclusion}

Altogether, the data shows that propolis didn't restore NO levels on ATL patients adherent cells. However, propolis pretreatment shows immunomodulatory effects on both healthy donors and ATL patients adherent cells, increasing IL- 4 and IL-17 and decreasing IL-10, in either the presence or absence of the L. braziliensis infection, demonstrating that propolis contributes with the decrease of the inflammation and could also contribute with parasite control.

\section{Acknowledgments}

This work was supported by the Coordenação de Aperfeiçoamento de Pessoal de Nível Superior (CAPES) - Brazil and Fundação Araucária - Brazil.

\section{Appendix A. Supplementary data}

Supplementary data associated with this article can be found, in the online version, at http://dx.doi.org/10.1016/j.cellimm.2016.09. 014.

\section{References}

[1] P. Kaye, P. Scott, Leishmaniasis: complexity at the host-pathogen interface, Nat. Rev. Microbiol. 9 (2011) 604-615.

[2] R. Reithinger et al., Cutaneous leishmaniasis, Lancet. Infect. Dis. 7 (2007) 581 596.

[3] N.C. Hepburn, Cutaneous leishmaniasis, Clin. Exp. Dermatol. 25 (2000) 363370.

[4] S. Sundar, J. Chakravarty, Leishmaniasis: an update of current pharmacotherapy, Expert Opin. Pharmacother. 14 (2013) 53-63.

[5] S. Nylén, S. Gautam, Immunological perspectives of leishmaniasis, J. Global Infect. Dis. 2 (2010) 135-146.

[6] G. Gupta, S. Oghumu, A.R. Satoskar, Mechanisms of immune evasion in leishmaniasis, Adv. Appl. Microbiol. 82 (2013) 155-184.

[7] S.L. Reiner, R.M. Locksley, The regulation of immunity to Leishmania major, Annu. Rev. Immunol. 13 (1995) 151-177.

[8] D. Sacks, N. Noben-Trauth, The immunology of susceptibility and resistance to Leishmania major in mice, Nat. Rev. Immunol. 2 (2002) 845-858.

[9] M.G. Pitta et al., IL-17 and IL-22 are associated with protection against human kala azar caused by Leishmania donovani, J. Clin. Invest. 119 (2009) 2379-2387.

[10] R. Novoa, IL-17 and regulatory cytokines (IL-10 and IL-27) in L. braziliensis infection, Parasites Immunol. 33 (2011) 132-136.

[11] M.S. Nascimento et al., Interleukin 17A acts synergistically with interferon $\gamma$ to promote protection against Leishmania infantum infection, J. Infect. Dis. 211 (2015) 1015-1026.

[12] S. Lopez Kostka et al., IL-17 promotes progression of cutaneous leishmaniasis in susceptible mice, J. Immunol. 182 (2009) 3039-3046.

[13] J.M. Sforcin, V. Bankova, Propolis: is there a potential for the development of new drugs?, J Ethnopharmacol. 133 (2011) 253-260.

[14] P. Olczyk, P. Ramos, K. Komosinska-Vassev, J. Stojko, B. Pilawa, Positive effect of propolis on free radicals in burn wounds, Evid. Based Complement. Alternat. Med. 2013 (2013) 356737.

[15] P. Olczyk et al., Propolis modifies collagen types I and III accumulation in the matrix of burnt tissue, Evid. Based Complement. Alternat. Med. 2013 (2013) 423809.

[16] R. Ikeda et al., Brazilian propolis-derived components inhibit TNF- $\alpha$-mediated downregulation of adiponectin expression via different mechanisms in 3T3-L1 adipocytes, Biochim. Biophys. Acta 2011 (1810) 695-703.
[17] F. Missima, J.M. Sforcin, Green brazilian propolis action on macrophages and lymphoid organs of chronically stressed mice, Evid. Based Complement. Alternat. Med. 5 (2008) 71-75.

[18] J.M. Sforcin, Propolis and the immune system: a review, J. Ethnopharmacol. 113 (2007) 1-14.

[19] R.O. Orsi et al., Immunomodulatory action of propolis on macrophage activation, J. Venomous Anim. Toxins 6 (2000) 205-219.

[20] S.S. da Silva et al., Brazilian propolis antileishmanial and immunomodulatory effects, Evid. Based Complement. Alternat. Med. 2013 (2013) 673058.

[21] M.M. Miranda et al., Nitric oxide and Brazilian propolis combined accelerates tissue repair by modulating cell migration, cytokine production and collagen deposition in experimental leishmaniasis, PLoS ONE 10 (2015) e0125101.

[22] D.C. Ayres, M.C. Marcucci, S. Giorgio, Effects of Brazilian propolis on Leishmania amazonensis, Mem. Inst. Oswaldo Cruz 102 (2007) 215-220.

[23] D.C. Ayres, T.A. Fedele, M.C. Marcucci, S. Giorgio, Potential utility of hyperbaric oxygen therapy and propolis in enhancing the leishmanicidal activity of glucantime, Rev. Inst. Med. Trop. 53 (2011) 329-334.

[24] K. Pontin et al., In vitro and in vivo antileishmanial activities of a Brazilian green propolis extract, Parasitol. Res. 103 (2008) 487-492.

[25] G. Duran et al., In vitro antileishmanial activity of Adana propolis samples on Leishmania tropica: a preliminary study, Parasitol. Res. 102 (2008) 12171225.

[26] G.M. Machado, L.L. Leon, S.L. De Castro, Activity of Brazilian and Bulgarian propolis against different species of Leishmania, Mem. Inst. Oswaldo Cruz 102 (2007) $73-77$.

[27] H. Ozbilge, E.G. Kaya, S. Albayrak, S. Silici, Anti leishmanial activities of ethanolic extract of Kayseri propolis, Afr. J. Microbiol. Res. Acad. J. 4 (2010) $556-560$.

[28] G. Girgin et al., Immunomodulatory effects of Turkish propolis: changes in neopterin release and tryptophan degradation, Immunobiology 214 (2009) $129-134$.

[29] S. Ansorge, D. Reinhold, U. Lendeckel, Propolis and some of its constituents down-regulate DNA synthesis and inflammatory cytokine production but induce TGF-beta1 production of human immune cells, Z. Naturforsch. C. 58 (2003) 580-589.

[30] K.W. Cheung et al., Brazilian green propolis and its constituent, Artepillin C inhibits allogeneic activated human CD4 T cells expansion and activation, J. Ethnopharmacol. 138 (2011) 463-471.

[31] M.K. Amarante et al., The effect of propolis on CCL5 and IFN- $\gamma$ expression by peripheral blood mononuclear cells from leishmaniasis patients, J. Pharm. Pharmacol. 64 (2012) 154-160.

[32] C. Panis et al., Trypanosoma cruzi: effect of the absence of 5-lipoxygenase (5LO)-derived leukotrienes on levels of cytokines, nitric oxide and iNOS expression in cardiac tissue in the acute phase of infection in mice, Exp. Parasitol. 127 (2011) 58-65.

[33] L. Proudfoot et al., Regulation of the expression of nitric oxide synthase and leishmanicidal activity by glycoconjugates of Leishmania lipophosphoglycan in murine macrophages, Proc. Natl. Acad. Sci. U.S.A. 93 (1996) 10984-10989.

[34] N. Wanasen, L. Soong, L-Arginine metabolism and its impact on host immunity against Leishmania infection, Immunol. Res. 41 (2008) 15-25.

[35] R. Lira, M. Doherty, G. Modi, D. Sacks, Evolution of lesion formation, parasitic load, immune response, and reservoir potential in C57BL/6 mice following high- and low-dose challenge with Leishmania major, Infect. Immun. 68 (2000) 5176-5182.

[36] W.N. Oliveira et al., The role of inflammatory and anti-inflammatory cytokines in the pathogenesis of human tegumentary leishmaniasis, Cytokine 66 (2014) $127-132$.

[37] S.L. Croft, K. Seifert, V. Yardley, Current scenario of drug development for leishmaniasis, Indian J. Med. Res. 123 (2006) 399-410.

[38] S.S. da Silva et al., Propolis reduces Leishmania amazonensis-induced inflammation in the liver of BALB/c mice, Parasitol. Res. 115 (2016) 15571566.

[39] K. Tan-No et al., Anti-inflammatory effect of propolis through inhibition of nitric oxide production on carrageenin-induced mouse paw edema, Biol. Pharm. Bull. 29 (2006) 96-99.

[40] R. Kumar, R.A. Bumb, P. Salotra, Correlation of parasitic load with interleukin-4 response in patients with cutaneous leishmaniasis due to Leishmania tropica, FEMS Immunol. Med. Microbiol. 57 (2009) 239-246.

[41] C.A. Lazarski et al., IL-4 attenuates Th1-associated chemokine expression and Th1 trafficking to inflamed tissues and limits pathogen clearance, PLoS ONE 8 (2013) e71949.

[42] Y. Yao, W. Li, M.H. Kaplan, C.H. Chang, Interleukin (IL)-4 inhibits IL-10 to promote IL-12 production by dendritic cells, J. Exp. Med. 201 (2005) 18991903.

[43] M.M. Kane, D.M. Mosser, The role of IL-10 in promoting disease progression in leishmaniasis, J. Immunol. 166 (2001) 1141-1147.

[44] Y. Belkaid et al., The role of interleukin (IL)-10 in the persistence of Leishmania major in the skin after healing and the therapeutic potential of anti-IL-10 receptor antibody for sterile cure, J. Exp. Med. 194 (2001) 1497-1506.

[45] A. Salhi et al., Immunological and genetic evidence for a crucial role of IL-10 in cutaneous lesions in humans infected with Leishmania braziliensis, J. Immunol. 180 (2008) 6139-6148.

[46] C. Fertin et al., Interleukin-4 stimulates collagen synthesis by normal and scleroderma fibroblasts in dermal equivalents, Cell. Mol. Biol. 37 (1991) 823829. 
[47] P. Gillery et al., Different regulation of collagen I gene transcription in threedimensional lattice cultures, FEBS Lett. 296 (1992) 297-299.

[48] A.E. Postlethwaite et al., Human fibroblasts synthesize elevated levels of extracellular matrix proteins in response to interleukin 4, J. Clin. Invest. 90 (1992) 1479-1485.

[49] S.S. Iyer, G. Cheng, Role of interleukin 10 transcriptional regulation in inflammation and autoimmune disease, Crit. Rev. Immunol. 32 (2012) 23-63.

[50] A. Kimura, T. Kishimoto, IL-6: regulator of Treg/Th17 balance, Eur. J. Immunol. 40 (2010) 1830-1835.
[51] C. Gonzalez-Lombana et al., IL-17 mediates immunopathology in the absence of IL-10 following Leishmania major infection, PLoS Pathog. 9 (2013) e1003243.

[52] V.S. Boaventura et al., Human mucosal leishmaniasis: neutrophils infiltrate areas of tissue damage that express high levels of Th17-related cytokines, Eur. J. Immunol. 40 (2010) 2830-2836.

[53] A.B. Guimarães-Costa et al., Leishmania amazonensis promastigotes induce and are killed by neutrophil extracellular traps, Proc. Natl. Acad. Sci. U.S.A. 106 (2009) 6748-6753. 